\title{
Mothers Unite!
}

\section{Organizing for Workplace Flexibility and the Transformation of Family Life}

\author{
Jocelyn Elise Crowley
}

\author{
ILR Press \\ an imprint of \\ Cornell University Press \\ Ithaca and London
}




\section{Copyright (ㅇ 2013 by Cornell University}

All rights reserved. Except for brief quotations in a review, this book, or parts thereof, must not be reproduced in any form without permission in writing from the publisher. For information, address Cornell University Press, Sage House, 512 East State Street, Ithaca, New York 14850.

First published 2013 by Cornell University Press

Printed in the United States of America

\section{Library of Congress Cataloging-in-Publication Data}

Crowley, Jocelyn Elise, 1970-

Mothers unite! : organizing for workplace flexibility and the transformation of family life / Jocelyn Elise Crowley.

p. cm.

Includes bibliographical references and index.

ISBN 978-0-8014-5175-1 (cloth : alk. paper)

1. Mothers-United States-Societies and clubs.

2. Women employees-United States-Societies and clubs.

3. Work and family-United States. I. Title.

$$
\text { HQ759.C94 } 2013
$$

$$
306.874^{\prime} 3-\mathrm{dc} 23 \quad 2012042157
$$

Cornell University Press strives to use environmentally responsible suppliers and materials to the fullest extent possible in the publishing of its books. Such materials include vegetable-based, low-VOC inks and acid-free papers that are recycled, totally chlorine-free, or partly composed of nonwood fibers. For further information, visit our website at www.cornellpress.cornell.edu.
Cloth printing
$\begin{array}{llllllllll}10 & 9 & 8 & 7 & 6 & 5 & 4 & 3 & 2 & 1\end{array}$ 
For Alan, Monica, and my mother, with incredible gratitude 


\section{Contents}

1. American Mothers, American Troubles 1

2. Power in Numbers 20

3. Why Join? 47

4. Do Mommy War Attitudes Prevent Organizing? 70

5. Workplace Flexibility Options 95

6. Are We in a Movement Now? Can We Get There? 143

7. Mothers Need Leadership, Too 174

Appendix: Research Methodology 193

Notes 209

$\begin{array}{ll}\text { Index } & 221\end{array}$ 


\section{Acknowledgments}

I started thinking about writing this book when I was reflecting on a particularly vivid memory from my childhood. My mother was a single parent, working two jobs (including weekends), and going to school in the evenings. Money was very tight then, and I remember that she had no access to paid time off in case my sister or I became ill and had to be pulled out of elementary school. I did not want to put additional stress on my family, so I tried very hard not to get sick. In my child's mind, I feared that if my mother lost an afternoon's wages picking me up from school, we might not have food on the table that night. That scare, that fright, has stayed with me until this day. This book aims to do something positive with those powerful, lingering emotions for all mothers and their children in the twenty-first century.

I thank the financial supporters of this project, without whom this book would have simply remained ideas loosely organized in my head. Thanks most of all to Kathleen Christensen at the Alfred P. Sloan Foundation for guiding the project to fruition. The Michael J. and Susan Angelides Public Policy Research Fund at the Edward J. Bloustein School of Planning and Public Policy at Rutgers was extremely generous in supporting the transcription of all the interview recordings included here. In addition, I benefitted from several Rutgers University Research 
Council grants, which helped with multiple parts of the project. Raymonde Pozzolano and her team offered excellent transcription services, as usual.

I am extremely grateful to the five mothers' organizations that are the subject of this book. Their leadership were kind enough to provide me with access to their membership and trusted me to tell their stories accurately. The mothers who actually participated in the study, by being observed, interviewed, or surveyed, also gave generously of their time. I learned so much from them, and they have changed my perceptions about the challenges of motherhood forever.

I am also grateful to the staff at Cornell University Press. My editor, Frances Benson, believed in the project from the beginning and helped guide it seamlessly to publication. Kitty Liu answered all my annoying editing and production questions without complaint. Special thanks to Susan Specter and Romaine Perin for their excellent copyediting skills. Of course, the anonymous referees greatly enhanced the value of the work across each chapter.

Personally, I wrote this book during a time in my life that was incredibly challenging. It helped to remember that, as I heard the television character Dr. Gregory House advise, "People get what they get. It has nothing to do with what they deserve." In addition to the help of a fictional protagonist, numerous real-life people supported me through this process. First of all, my colleagues at Rutgers went above and beyond the call of duty in helping me with this effort-Dr. Marc Weiner and Dr. Kelly Dittmar in particular-I am looking at you! Liza Viana, Melissa Chedid, and Vanessa Alger also provided excellent research support. Second, my friends and close family built a firewall around me as I continued to write. Maryann Barakso, Elizabeth Wood, Theresa Luhm, Amy Schapiro, Sandhya Higgins, Ellen Braitman, John Spry, Michelle Wilson, Susan Crawford Sullivan, Suzanne Glaser-thank you for listening. You constantly pointed to the light at the end of the tunnel that on many days I could not see. Most important, my mother, my sister Monica, and my husband did incredible amounts of hand-holding as I assembled the manuscript. I cannot thank them enough, and I dedicate this book to them. And, of course, M. B. Crowley's support never wavered. Don't worry, my precious angel, I will see you soon. 
Mothers Unite! 


\section{American Mothers, American Troubles}

After graduating from Harvard Law School in 1988, a young woman named Michelle joined the law firm of Sidley Austin in Chicago, where she specialized in corporate transactions. The job offered more than an introduction to the complex world of legal analysis and maneuvering. When a handsome young summer associate came to work there, it took her only a little while to realize that she had met her romantic match.

With a partner whom she eventually married at her side, Michelle saw her career begin to rise as she moved on to challenging new opportunities. In 1991, after leaving Sidley, Michelle went to work for the Chicago mayor's office; there she helped promote urban economic development in underserved neighborhoods. She then moved on to the Chicago Transit Authority to become head of the citizens' advisory board. Later, she ran the nonprofit organization Public Allies, which trained young people for careers in public service by helping them secure internships. Following that experience, she went to the University of Chicago, taking a job in student services and initiating a new community-based program in order to enhance city-college interactions. By 2005, she had become vice president for community and external affairs at the University of Chicago Medical Center.

These career moves all ended in 2007, when the handsome young associate with whom she had fallen in love years ago at Sidley Austin-a man named Barack Obama-decided to run for president. With two young 
daughters, Malia, born in 1998, and Sasha, born in 2001, Michelle took a leave of absence from her job to help her husband campaign. When he became president, she permanently quit her paid job and declared her new employment intention to be mom in chief to her daughters. ${ }^{1}$

Michelle Obama's story is, in many ways, a common one: that of the modern American middle-class mother. Each part of her tale resonates with some trace of who we were in the past and who we are now. That is, some of us can relate to the young woman, fresh out of school, trying to make a name for herself in the competitive professional world. Others are drawn to her quest to fulfill her true passions, whether they be in the corporate or nonprofit world. Still others focus on, ponder, celebrate, and critique her decision to devote herself to her family in recent years by dropping out of the paid labor force.

Perhaps, though, what is most compelling about Michelle's story is that it is intriguing not only because of these distinct parts of her life but also because of the compelling push and pull of the forces that emerged over the complete trajectory of her evolution as a modern woman. She faced decisions that many middle-class mothers must confront as they experience the birth and then the numerous stages of their children's development. When, exactly, should they have children? If they are working, how much time should they take off? Should they even return to the paid workforce at all? If they do return to work, who will take care of their children? Can they even afford not to work? What is the best arrangement for them, their families, and their children? How do they know that they have made the right decisions?

What is also compelling about Michelle Obama's life course is that it truly mixes the complex reality of personal and public decision making regarding if and how mothers pursue paid work in the United States. In this context, personal decision making means the range of individual choices mothers have within their reach about the future of their lives. Clearly, mothers make decisions about their educational and occupational pursuits all the time. With more resources at their disposal, such as a higher socioeconomic status and networking connections, many mothers have a broader array of choices that they can pursue. They can work in a demanding field, work part time, or not work for pay at all. They can purchase services that help them manage their lives, services such as high-quality child care and housekeeping assistance. Yet their 
stress levels may still be high. Isolation, if they elect to stay at home, and feelings of being overwhelmed by paid work and family responsibilities, if they remain employed, are commonplace among this group of mothers.

Mothers with fewer resources on hand still have the ability to make personal decisions about paid work, but their choices are much more limited. Because they earn lower wages, staying at home with their children may not be financially possible. The jobs that they hold are likely to have few, if any, benefits and to require unpredictable or irregular hours. On the other hand, since child care costs are likely to be proportionately very high if they were to work in a low-wage job, staying at home might be the only option that they have. They would then need to rely on a partner, other family members, or public benefits in order to pay their bills. For these mothers, then, psychological, emotional, and physical strains can quickly emerge under the best of conditions.

Regardless of socioeconomic status, most mothers still struggle with whether the arrangement that they have ultimately established is most suitable for their families. Guilt on all sides runs rampant. Yet all of these mothers' arrangements are debated by media pundits in a very different way under the label of the "Mommy Wars." In this oversimplistic narration, personal decisions about a mother's level of paid labor force participation are not complex all. Instead, they are made by onedimensional characters who believe either that working for pay is better or that staying at home is better. Anyone who makes a decision that does not mirror her own is a "bad mother."

While mothers with many and those with limited resources are both able to exercise a certain degree of personal autonomy over the structure of their work and family lives-and the media's portrayal of the Mommy Wars almost exclusively focuses on these individual "choices"-it is important to recognize that public decision making can also expand or contract the scope of power they have over the nature of the paid work options they face as well. In this context, public decision making pertains to the range of opportunities and actions offered by firms, organizations, and all levels of government that can influence individuals' lives. These can include critical initiatives in the form of child care options, health care benefits, and other types of employee assistance. However, in this book I am concerned with one central aspect of public decision making as it affects mothers' opportunities in 
particular: workplace flexibility policy. And I ask a series of fundamental questions related to the potential for political activism to emerge on this issue: do women want to come together to build a new mothers' movement on behalf of promoting more flexible work options? Can they? Should they?

\section{What Are Workplace Flexibility Policies?}

Simply put, workplace flexibility policies are any initiatives that provide workers with options regarding the structure of their work lives. More concretely, workplace flexibility can be broken down into three critical areas: flexible work arrangements; time-off options; and career exit, maintenance, and reentry pathways. ${ }^{2}$

Flexible work arrangements represent the first component of workplace flexibility. When these options are in place, employees exercise some control over the timing of their work day, their location of work, or both. Concrete examples include the provision of alternative work schedules (i.e., nontraditional start and end times or compressed workweeks) and advanced knowledge of overtime possibilities, predictable scheduling, and defined break schedules. Part-time work, job shares, or part-year work are also part of flexible work arrangements. Last, workers may also have the opportunity to work at home or at an alternative location. Research has consistently shown the benefits to workers of these policies. For example, employees are more likely to be engaged and satisfied with their jobs when they are granted these new options to manage their work time. ${ }^{3}$ Flexibility can also substantially decrease stress and burnout among workers and can actually improve concrete measures of physical health, such as lowering cholesterol levels. Health outcomes are thought to improve because workers have a greater sense of control over how their lives are scheduled in their totality. ${ }^{4}$ Finally, employees are likely to have lower degrees of work-family conflict and an increased sense of work-family balance, possibly also because of their enhanced autonomy over the management of their time. ${ }^{5}$

Time-off options represent the second element of workplace flexibility. Guaranteed short-term time off, for example, provides workers with the ability to properly respond to planned or unplanned events. Examples include attending a child's school event, taking care of a personal 
illness, and addressing the illness of a loved one or a medical or home emergency. Also under this category are both episodic time off to handle recurring appointments or life issues (medical treatments, community service, advanced education) and extended time off to deal with an issue that lasts longer than five days but less than one year (taking care of a child or loved one, having a severe health issue, serving in the military|. Shorter time off is beneficial for all workers, but especially for those working in low-wage jobs; those on the bottom rungs of the employment ladder in particular have little room in which to adjust their schedules to meet their own as well as their families' medical needs. ${ }^{6}$ Of course, for longer periods of time off, the United States has in place the Family and Medical Leave Act, which provides up to twelve weeks of unpaid leave for workers in organizations with fifty or more employees. For those workers who do qualify, this leave, and probably leaves like it, enable mothers to return to their jobs without significant wage and career advancement penalties. ${ }^{7}$

Career exit, maintenance, and reentry pathways represent the last component of workplace flexibility. Workers use these policies to either decelerate or accelerate their careers when confronted with severe or time-consuming changes in their lives, such as new caretaking responsibilities or health care needs. ${ }^{8}$ Examples of exit and maintenance strategies would be opportunities for part-time work and continued education. Reentry pathways would include employer initiatives such as the active recruitment of those workers who may have been out of the workforce for a significant period or the creation of job fairs in areas where underrepresented workers live. These types of policies are especially important to mothers, who may prefer working part time to not working at all. Mothers also might have substantial gaps in their résumés if they have taken months or years off to raise their children. ${ }^{9}$

While there are clear benefits to employees from having workplace flexibility, research has documented significant gains to employers as well. More specifically, workplace flexibility options are central to attracting the best possible talent to a set of jobs. ${ }^{10}$ Not surprisingly, good workers want to be where such options are offered, valued, and supported. By extending such options, employers gain employees who are more committed to their work and, hopefully, are therefore able to retain them for longer periods of time. This retention is essential because the cost of finding new employees can be excessively high. 
Implementing advertising strategies, deploying headhunters, using human resource managers, and retaining relocation-assistance consultants can all cost firms significant resources. It makes sense, therefore, for firms to try to avoid these expenses. Indeed, research has documented that companies tend to retain strong talent when they create specialized initiatives that assist mothers who are temporarily leaving work and planning to return a short time later. ${ }^{11}$

Employers also obviously care about absenteeism. Without dependable workers able to execute the tasks of their jobs on a daily basis, firms suffer in terms of their bottom line. This can be especially true for small companies, for which any missing worker can cause a disproportionate impact on productive output. While workers can be absent for various significant reasons, happiness and a sense of well-being at their place of employment can prevent unnecessary days off. Again, here, too, it makes sense for employers to be attentive to the workplace environment. Indeed, several studies have indicated that firms that offer more flexibility options have lower rates of absenteeism than those that do not. ${ }^{12}$

Yet American work culture is difficult to change, and employers have vocalized concerns about these policies. ${ }^{13}$ Many supervisors have grown up in a context in which all their employees are expected to be "ideal workers," dedicated and available to their jobs 100 percent of the time. ${ }^{14}$ Believing in this ideal-worker ideology, these employers fear the reactions of their customer base should their workers not be physically present on a consistent, "traditional" basis. Some types of jobs may be ill suited for flexibility, for example, when employees must work as a team on a similar schedule toward a common goal. Furthermore, there are employers who are afraid of employee abuse of these new options and of their inability to properly monitor worker activities. Small businesses in particular may be wary of any type of time-off policies or worker exit and reentry policies because of the costs they might face in either holding jobs for these employees or in training new workers.

These fears are reflected in the relatively low levels of flexibility employers currently offer their employees. According to the 2008 Study of Employers by the Families and Work Institute, a nonprofit organization dedicated to generating research about the modern, changing workplace, employers vary to an extraordinary extent in what they are willing to consider offering in terms of flexibility. For example, 
concerning flexible work arrangements, while 79 percent of employers allow at least some of their employees to vary their start and stop times, only 23 percent permit employees to work at home for part of the day. Likewise, for time-off options, 73 percent of employers permit some of their employees to take time off during the day to attend to personal matters, without pay, but only 47 percent allow their workers to engage in voluntary work during the work day. Finally, with respect to career exit, maintenance, and reentry, 74 percent of employers consent to some of their employees taking paid or unpaid leave to improve their educational level or skill set, but only 38 percent will provide some of their employees with a sabbatical from work (six months or more) and a guarantee to return to a comparable job. ${ }^{15}$ It is critical to note that these statistics also reflect employers' reporting that they offer these benefits to "some" of their employees. When employers are asked if these options are offered to "all or most" of their employees, these numbers drop dramatically. Overall, these statistics demonstrate that there is clearly room for a dramatic expansion in workplace flexibility options for the great majority of American workers.

It is also important to note that to the extent that flexibility exists, it is primarily a benefit for workers with higher levels of education. This is true for several reasons. First, employers frequently view flexibility as a form of compensation, and thus the higher the level of education an employee has (and therefore the higher the level of his or her pay), the more likely that worker is to receive flexibility. Second, employers often have concerns about giving lower-wage workers flexibility due to fear of increased management costs. For example, in the retail or food sectors, personnel must be reliably on hand to meet the needs of a steady stream of consumers. When workers have flexibility, supervisors need to expend extra effort in making sure that schedules are covered. Overall, though, regardless of a particular employee's level of education, workplace flexibility is clearly not a possibility for sizeable numbers of American workers. ${ }^{16}$

In addition to differences in who are actually offered these policies, there are disparities in policy uptake. On this point, studies have shown that men and women use flexibility policies at different rates. While there are many similarities between men and women-for example, research has shown that at incomes lower than $\$ 25,000$ men and women use flextime at about the same rate-at higher levels of income, the sexes 
diverge. More specifically, men are more likely to use flextime when family incomes range from $\$ 25,000$ to $\$ 74,999$; interestingly, women assume higher rates at family income levels at $\$ 75,000$ and above. ${ }^{17}$ Other scholarship suggests that men and women use flexibility policies at the same rate when they are childless or have adult children, but that women are more likely to use a subset of them such as job sharing, telecommuting, part-time work, and flextime when there are young children present in the home. ${ }^{18}$

While flexibility might be offered on paper, workers might be hesitant to use it. In fact, there is a strong work culture that promotes the notion of the ideal worker in the United States; this is the type of employee referred to earlier, heavily committed to her job and available to her supervisors twenty-four hours a day. ${ }^{19}$ So, companies may have both formal and informal policies that supposedly encourage flexibility, but workers may fear using them if they perceive that they will encounter some type of harm to their career in doing so, such as pay and promotion penalties. Flexibility policies must be viewed by workers as usable, without any supervisor retribution, for them to be helpful, but the reality is that many workers shy away from even broaching the topic within their organizations. ${ }^{20}$

But what if mothers could come together as a unified group and demand flexibility? In this book I examine the interesting phenomenon of women joining the largest and most influential mothers' organizations in the United States, groups that, although presenting different approaches to the issue of workplace flexibility, all implicitly or explicitly endorse it. Not surprisingly, groups with a higher percentage of mothers who work for pay tend to stress in their policy positions an activist role for firms and the government regarding workplace flexibility, while groups with more stay-at-home mothers tend to advocate more individual responsibility in establishing satisfactory work-life arrangements. Despite these public positions, however, little is known about group members' true opinions on this critical employment issue. The puzzle that I seek to solve is whether support for workplace flexibility as a general principle can unite members across these divergent groups, potentially creating a viable mothers' movement. If so, all these groups can then become vehicles for mobilizing action as they strive to make the lives of all American mothers more productive, sustainable, and meaningful over time. 


\section{Why Study Mothers Organizing in the United States?}

The groups that are the focus of this study include Mothers of Preschoolers (MOPS), Mocha Moms, Mothers \& More, the National Association of Mothers' Centers (NAMC), and MomsRising. Each group will be described in detail over the course of the next several chapters. First, however, it is important to lay out the proper contextual foundation for studying them. There are two main issues at stake: why this book focuses on mothers rather than both fathers and mothers, and why it examines mothers' groups in particular rather than parents' groups.

Workplace flexibility clearly affects both parents-mothers and fathers-and their ability to lead happy, satisfying lives. And undoubtedly, fathers have become more involved in raising their children over time, making workplace flexibility a critical issue for them as well. However, biology still demands that mothers carry children during pregnancy, and a significant number of mothers want to breastfeed after their babies are born. These realities require that mothers remain with their children for an extensive period after birth. Moreover, although fathers are contributing greater levels of care to their children, mothers still carry the disproportionate burden of responsibility in this area even after the breastfeeding years are over. On average between 2005 and 2009 , for example, while fathers spent 1.22 hours a day doing household chores, mothers spent 1.98 hours. Mothers also spent 1.24 hours a day on helping and caring for household members, including children, in contrast to .87 hours a day for fathers. ${ }^{21}$ With family demands more predominantly experienced by them, then, mothers are more likely than fathers to press for change in the area of workplace flexibility. It is for these reasons that I examine mothers rather than both parents as agents of transformation in the realm of workplace flexibility. I also focus on mothers' groups in particular rather than parents' groups as the locus of such change. And why? Collective action in the form of group initiatives drives the restructuring of life in American politics. But notably, mothers more frequently than fathers organize in American politics in their role as parents. In fact, mothers organizing with one another on behalf of shared goals has a rich history across the American political landscape..$^{22}$ In some cases, their campaigns have been very loud and visible, while in other cases, their mobilizing efforts have been more quiet and behind the scenes. 
What were the largest and most geographically expansive mothers' groups that preceded those studied in this book? ${ }^{23}$ And what can be learned from them in their attempts to effect policy change? In the nineteenth century, a number of groups formed with the aim of helping both mothers and children confront the health and education issues of the day. The General Federation of Women's Clubs (GFWC) was started in 1890 under the direction of Jane Cunningham Croly; it began as a network of local women's groups, then became an association of state federations. While at first the organization attracted mostly white middle-class women into its ranks, as it evolved, working-class women became involved as well; tragically, as a result of racism, African Americans were largely excluded. ${ }^{24}$ While the organization worked on issues unrelated to motherhood, such as supporting American troops in wartime, it also engaged in multiple activities that directly benefited children. For example, it became deeply involved in the creation of public libraries across the United States as well as in the development of kindergartens. Also on its radar were the issues of child labor and health. With the assistance of Jane Addams, the organization helped create a Child Labor Committee to improve the safety of child workers. By 1916 , more than two thousand clubs had joined together to confront the problems of infant and maternal mortality. ${ }^{25}$ Their activism ultimately helped produce the 1921 Sheppard-Towner Act, which mandated federal funding for child and maternal health.

Because African American women were prohibited from joining the GFWC, they started their own organizations to deal with issues affecting their communities. ${ }^{26}$ Two critical African American leaders-Josephine Ruffin and Mary Church Terrell-started the National Association of Colored Women's Clubs (NACWC) in 1896. During its initial years of operation, the group largely focused on campaigns around women's suffrage, as well as protests against lynching and Jim Crow laws. However, over time, the NACWC, like the GFWC, also became involved in a classic mothers' issue: improving the quality of children's education.

At the end of the century, in 1897, under the leadership of Phoebe Apperson Hearst and Alice McLellan Birney, the National Congress of Mothers was founded, with a primary focus on improving children's education. Despite opposition from school administrators, its founders were committed to the idea that parents, and at the time particularly mothers, become involved in their children's intellectual development. 
During this new era of progressive politics, the organization distinguished itself by lobbying for federal aid for elementary schools, enhanced teacher salaries, and the extension of juvenile courts. ${ }^{27}$ Like the GFWC, it argued that kindergarten was critical and helped implement such programs across the country. It also helped create the United States Children's Bureau in 1912, now under the Department of Health and Human Services, which works on such issues as child labor, child abuse, general living conditions, child welfare, and infant mortality. ${ }^{28} \mathrm{It}$ officially became the Parent Teacher Association (PTA) in 1924.

Whereas these organizations focused on mothers' relationships to their children's health and education, another key mothers' organization that formed during this time dealt with the conditions under which mothers could and should have children at all. Margaret Sanger set up her first office in Brooklyn, New York, in 1916, providing birth control information to largely poor and immigrant women, and in 1921 founded the American Birth Control League. ${ }^{29}$ Sanger effectively fought against the Comstock Laws, which since the 1870s had made it illegal to give out information about birth control. By 1942, the organization had become the Planned Parenthood Federation of America and later went on to provide such services as the testing for and treatment of sexually transmitted infections, sexuality education, pregnancy testing, breast cancer screening, abortion services, and general reproductive health counseling.

Around the mid-twentieth century, a series of mothers' groups emerged that advocated for the ability of all women to provide for their children economically. The National Welfare Rights Organization, begun in 1966 under George Wiley, was typical of these groups. ${ }^{30}$ Its mission centered on helping single-parent families, many of whom were African American and receiving welfare benefits. At this point in American social policy history, conservatives were increasingly arguing against spending more money on welfare programs. To counter these efforts, local churches and other organizations attempted to voice the needs and concerns of their communities, but individually, they were unable to make an impact on the tide of antiwelfare sentiment that was then sweeping the country. To address this problem more uniformly, the National Welfare Rights Organization pooled these voices into its one central mouthpiece to fight for such desired outcomes as adequate income, dignity, justice, and the right to democratic participation for 
welfare recipients. ${ }^{31}$ Its central goal was to influence the debate on welfare reform proposals then being addressed in Congress, and the group made protecting livable benefit levels in the Aid to Families with Dependent Children (AFDC) program and the defeat of Nixon's proposed Family Assistance Plan (with low minimum-benefit levels) a priority. They continued their work apace before disbanding in 1975.

There were also the stirrings of attempts to redefine nutritional practices as they related to breastfeeding. La Leche League began in Chicago in 1956, under the primary tutelage of Mary White and Marian Thompson, to help promote breastfeeding among the general population. This was quite a radical idea at the time, since bottle feeding was becoming increasingly popular across American society. ${ }^{32}$ Breastfeeding was also a countercultural idea in that women were moving from the home and into the workforce, giving them fewer opportunities to nourish their infants in this way. However, members of the league believed in the value of what they were promoting and maneuvered to turn conventional wisdom on its head regarding what a modern workplace should look like. The league argued that workplaces should accommodate breastfeeding by providing private mother-baby spaces and promoted the use of the electrical breast pump for times when mothers could not directly feed their infants. Their ideas made slow but steady inroads among mothers most interested in integrating modern workplaces with novel breastfeeding practices.

A last set of mothers' organizations formed in the later part of the twentieth century to protect their members' children from physical harm. Candy Lightner and Cindi Lamb began Mothers Against Drunk Driving (MADD) on September 5, 1980. Both women were personally affected by drunk drivers: Lightner's daughter had lost her life and Lamb's daughter had become paralyzed as a result of accidents involving the other driver's excessive use of alcohol. ${ }^{33}$ MADD became an extremely important organization in American political life because it brought a completely unique perspective to the issue of drunk driving. Prior to its establishment, the media had focused on the cold statistics of alcohol-related injuries and deaths on the road, and car makers had directed their energies toward improving safety in vehicle construction rather than educating drivers on the importance of not drinking while driving. MADD was different; it gave a human face to the problem of drunk driving. Among its many accomplishments, MADD assisted in 
the enactment of stricter state laws against drunk driving, helped establish the new federal drinking age of twenty-one, and advocated for lower blood alcohol levels in defining legal inebriation. ${ }^{34}$

In another initiative to protect children from physical harm, the Million Mom March began as a rally held on Mother's Day, May 14, 2000. Donna Dees-Thomases, a New Jersey mother, had become increasingly horrified by the random gun violence occurring across the United States, especially violence directed at children. Along with several dozen other mothers, she applied for a permit to hold a march on the Washington Mall to protest what she felt was a lack of effective gun laws in the United States. The march attracted approximately 750,000 people, with an additional 150,000-200,000 marching in other locations across the country. ${ }^{35}$ This initial rally later transformed into an organization with seventy-five local chapters; these work directly with the Brady Campaign to End Gun Violence, a well-respected nonprofit that raises awareness about gun violence in its various manifestations.

The Working World, a Mother's Place, and Modern Mothers' Organizations

Historical mothers' groups, as well as the five modern, national mothers' groups at the center of analysis here, all share the same fundamental goal: making the lives of their members and of their children more meaningful. While not always successful in achieving all their objectives, the historical organizations generally laid out clear public policy goals that attracted the passion of their members. This is true also of the five modern groups studied here; they all in some way have identifiable positions related to one key issue: promoting workplace flexibility. These five groups were thus chosen for study because of this overlapping issue of interest, but also because they are the only national groups that have members across multiple states and maintain centralized lists of their memberships, which is vital to the research design employed here. ${ }^{36}$ But because of the many other roles that these groups play and the multiple issues on which they focus their attention, it is not clear where their members themselves stand on the advancement of workplace flexibility initiatives. Is there unity between these groups' public positions and their members' views, or divergence? Can a mothers' 
movement be built across all the groups, with workplace flexibility taking center stage? After all, constructing a mothers' movement in the twenty-first century over such a large population certainly can seem like a gargantuan task. ${ }^{37}$

In many ways, the origins of these five modern mothers' groups are fascinating. They were propelled into existence as a result of the massive upheaval in women's labor force participation that has occurred over the past fifty years. More specifically, the number of married women with children under eighteen in the American paid labor force skyrocketed during this period. In 1960, only 27.6 percent of these women were engaged in paid employment. By 1980 , that number had grown to 54.1 percent and by 2010 had reached 71.3 percent..$^{38}$ The reasons behind these changes were numerous. Women were having smaller families, enabling them to focus on external interests. At the same time, men's real wages were falling, and mothers entered the paid labor market in financially supporting their families, to maintain their standard of living. Finally, the women's movement opened up educational opportunities for mothers and encouraged them to find self-satisfaction through paid employment. As a result of all these factors, mothers became a permanent fixture in the contemporary American workforce.

The road to paid work, however, was rocky. ${ }^{39}$ Women struggled with the decision of how best to combine paid work (if at all) and unpaid work on a variety of fronts..$^{40}$ To cope with the diversity of these workfamily challenges, mothers began turning to one another and joining organizations with various approaches to the topic of workplace flexibility. On one end of the spectrum is Mothers of Preschoolers (MOPS). Established in 1973, it stresses Christian values among its membership and participating local chapters must adhere to its religious doctrines. The majority of its approximately eighty-five thousand members stay at home; however, it encourages women who both stay at home and work for pay to join. ${ }^{41}$ While it has no explicit policy on workplace flexibility, it does encourage personal fulfillment among all its members, and this may include these mothers putting together effective plans to engage in paid work.

In the middle of the organizational spectrum are Mocha Moms, Mothers \& More, and the National Association of Mothers' Centers (NAMC), each of which has approximately 50 percent of its members working for pay. Mocha Moms began in 1997 and has about twenty-eight hundred 
members. While Mocha Moms has a concrete mission to serve at-home mothers of color, because many of its members want to work for pay at least on a part-time basis, the organization actively helps them establish flexible, at-home businesses. Mothers \& More, with a membership of about fifty-three hundred, began in 1987 initially as an organization to help mothers transitioning in and out of the workforce, depending on their children's ages. It currently has a three-pronged advocacy and education statement in place called the Power Plan; one component of this plan is a fight for the ability of mothers to combine paid work with caretaking-including using workplace flexibility policies-if they so choose. NAMC started out in 1975 with a social work orientation and the goal of assisting mothers going through challenges with newborns. It later added a workforce advocacy component to its mission, embodied by its Mothers' Declaration of Rights, which states that mothers should be able to be caregivers as well as paid workers if they so desire. Inherent in this principle is that mothers be afforded flexible work opportunities. NAMC sponsors numerous work-life programs, such as conferences and blogs for its approximately nine hundred members.

At the opposite end of the spectrum from MOPS is MomsRising, an online group that expressly advocates for mothers working for pay. Formed in 2006, it has 169,000 members, the majority of whom are employed. Its primary advocacy mission is focused on improving the lives of mothers, around which workplace flexibility issues are central.

Along with the fact that these groups have different explicit perspectives on the issue of workplace flexibility is a real question of how much their positions are reflective of their members' actual belief systems and whether or not these belief systems can be mobilized into political action. For instance, how do each group's members view the concept of workplace flexibility overall? Do the members believe that it is relevant to their lives as mothers, or do only mothers who are currently working for pay have strong opinions about it? Do members of some groups tend to support all types of governmental workplace flexibility initiatives, such as tax breaks, educational efforts, and mandates on firms that implement such policies, while members of other groups tend to reject them? Are there major differences within groups, across groups, or again, depending on members' paid work status on these reform proposals? Considering the answers to all these questions together, are these mothers' group members more unified than divided on the issue 
of workplace flexibility, thus enabling them to build bridges in their approaches to solving problems facing the majority of mothers today? If so, then there are many as of yet untapped opportunities to promote intergroup mobilization and unite mothers definitively for the long term.

\section{Research Methodology and Plan of the Book}

Despite their importance in helping us understand the workplace and caregiving challenges that American mothers face in contemporary life, these five organizations simply have not had the resources to undertake a large-scale research project related to the attitudes, opinions, and behaviors of their membership bases..$^{42}$ In this book I seek to fill this knowledge vacuum through the use of three distinct research methodologies.

First, the analysis involved a random sample web-based survey of each group's membership in the spring of 2009 (final total sample size: 3,327); to generate comparative sociodemographic data, the study also included a phone-based random sample survey of eight hundred nongroup mothers during the same time period. To qualify for the phone survey, each respondent had to be at least eighteen years of age, have responsibility for at least one child age seventeen or under living in the home, and could not be a member of any of the five mothers' groups participating in the web survey. The random sampling design involved in each survey ensures that statements can be made about group mothers or nongroup mothers within a range of certainty. For example, if the surveys state that $\mathrm{x}$ percent of mothers involved in one group report being Hispanic, then it is also true that within a certain degree of certainty $\mathrm{x}$ percent of the entire group's population is Hispanic.

Second, during the period 2008-9, 125 in-depth interviews (25 per group/ were conducted with members involved in these groups, to provide the survey data with richness and depth. These interviews offer the most important source of contextual material for the book in their portrayal of mothers struggling with work-family balance, a struggle that the survey data can outline only in numerical form. ${ }^{43}$

Third, each group was observed during one of its meetings and notes were taken on the proceedings (for MomsRising, the online group, there was a moderated, structured online chat) in 2008-9. This triangulation of methods-surveys, interviews, and observation-strengthened the 
reliability and validity of the findings generated here. Further description of the survey methodology, as well as a list of the in-depth interview questions, are found elsewhere in the appendix.

The plan of the book is as follows. In chapter 2 I provide a more detailed history of the five organizations included in this study, describing their origins, development, and current missions. I pay particular attention to the position each organization has on workplace flexibility and the implications of the position for its members. I then use the nationally representative survey data to present a portrait of exactly who is joining mothers' groups today. I examine the sociodemographic profile of mothers who are currently members of these groups across the country, thereby providing a sense of what types of women are looking for support in the form of an organizational community of parents. In the chapter I also present sociodemographic data on the mothers who participated in the in-depth interviews.

In chapter 3 I then explore exactly why women have been motivated to join these special groups that serve mothers with varying degrees of attachment to the paid labor force. Throughout their children's development from infancy through adolescence, many mothers find that they need interpersonal support. Yet with current patterns of residential life that frequently spread families and friends widely apart geographically, mothers need to find their own methods of coping with the stresses of everyday parenthood. ${ }^{44}$ For women in the paid workforce, their place of employment may not be ideal for discussing the difficulties they face in their personal lives. ${ }^{45}$ They may feel anxious over proving to their supervisors and co-workers that they are serious workers and not overly distracted by family problems. They also might want to keep their family life issues to themselves. Of course, stay-at-home mothers might have even fewer opportunities to meet with and obtain support from other women experiencing parenting and other types of familial challenges. In this chapter I thus analyze mothers' groups for their ability to provide a whole host of resources to women, including day-to-day assistance with parenting information and forums to better manage their work-family balance conundrums.

In chapter 4 I discuss whether the reportedly deeply held divisions between stay-at-home mothers and mothers who work for pay actually exist. The media has repeatedly highlighted such divisions under the label "the Mommy Wars." Indeed, from morning and daytime television 
to popular books and advice gurus, is seems that no one can escape the sharp force of the weaponry generated by these wars. With the issue's saturation coverage, this chapter importantly notes that in the majority of cases, mothers are not judgmental of one another. Instead, they empathize with each mother's unique situation. Despite this common ground, this chapter does reveal that in a minority of cases, stereotypes of each group still exist, thus making mutual understanding a top priority of any modern motherhood movement.

While chapter 4 draws attention to the commonalities and only the small number of differences that drive mothers apart, in chapter 5 I delve into workplace flexibility as a unifying concept for bringing all mothers together. I explore across groups and the work-for-pay/stay-athome divide the question of whether mothers tend to support various workplace flexibility initiatives. In addition, I explore the levels of support that exist for governmental policies promoting workplace flexibility, ranging from educating firms about the benefits of such options, to tax breaks for companies that offer such plans, to mandatory requirements that organizations offer employees processes through which to request and even receive such arrangements. In doing so, I offer possible parameters for policy makers to think about as they design reforms to generate the widest levels of public support.

In chapter 6 I ask the direct question of whether the mothers who are participating in these groups now believe that they are participating in some type of mothers' movement through their organizational affiliation on the issue of workplace flexibility. The chapter then moves on to the question of whether workplace flexibility can provide a foundation for such a movement in the future. As the book will have demonstrated up until this point, the research behind workplace flexibility in terms of helping workers, and in particular mothers, manage their work and family lives is quite substantial. In addition, the organizational infrastructure to help effect change on the political level has already been established by these groups. What additional measures are necessary, then, to articulate flexibility as the critical workplace goal to be achieved in this new century?

In chapter 7 I directly consider the concrete steps that must be taken for workplace flexibility to become a viable part of the American employment structure. First, I examine the leadership that is essential in the world of public policy, such as lawmakers' educating the public 
and promoting incentives for businesses to become more engaged on this topic. I also explore the role of legal mandates in promoting change in the current political climate. Second, I focus on the leadership that must come from the groups that are spotlighted in this study. I point out the ways in which these groups could become more vested in the clear workplace flexibility desires of their members, which could ultimately harbinger the changes a unified mothers' movement could dramatically bring to fruition across the nation. 


\section{Power in Numbers}

The scene is a Roman Catholic Church basement in a large city on the East Coast. While there is only a little natural light breaking into the room through the small windows, the space is brightened by both the blue tile floor and the mood of the participants. There are twelve African American mothers from the group Mocha Moms enjoying snacks in a circle. Their children are seated at an adjacent table. It is a cold weekend morning right after the 2008 presidential election and the kids are happily coloring Barack Obama pictures. In the midst of this joyous celebration, the chapter president calls the group to order. The members then begin a lively discussion about the implications of this presidential election on their group's future agenda.

Mocha Moms President: Yes, we did! (referring to Obama victory). Where was everyone when you heard the news that Obama won?

Mocha Moms Member i: Was anyone worried that he wouldn't win? ...

Mocha Moms Member 2: I started crying because my daughter gets to see people like me in that office. I want to create change, too.

Mocha Moms Member i: Obama inspires people. The prayer and hope is that he is able to make change. 
Mocha Moms Member 3: My mother-in-law grew up in the segregated South and she still watches political shows. The older folks can't believe it ...

Mocha Moms Member 4: I bought a book for my six-year-old girl about Obama. In the book, it talks about him waking up early to do his homework.

Mocha Moms Member 2: How do we [take advantage of this change and] affect what happens outside this group?

In November 2008, these Mocha Moms members were clearly excited. Barack Obama had just been elected president, and they viewed this as a teachable moment for their children and their communities. Most important, they wanted to harness the momentum of the event to produce positive outcomes for their group chapters and beyond. But clearly this group was not starting from zero in terms of resources. There was decisive energy in the room and a strong sense of sisterhood among its members. This was a group with a vibrant and engaged history.

How did mothers' organizations like Mocha Moms-specifically MOPS, Mothers \& More, NAMC, and MomsRising-come into being in the associational landscape? How have the groups changed over time, in both scope and mission? What does each group's membership look like now, specifically with respect to its sociodemographic characteristics?

While mothers' groups have clearly emerged from the changing economic landscape of the past several decades, in each case, it took the initiative of one or a small set of leaders to begin a conversation about how they wanted their lives to be transformed through a new organizational community. Notably, these emergent leaders were each in a variety of circumstances, from working for pay, to transitioning into or out from the workforce, to staying at home. Nonetheless, across all five groups, the leaders perceived a sense of dissatisfaction, stress, and feeling of disenchantment with their lives as mothers. They therefore sought out mothers like themselves to find support and fulfill other needs that were so important to them at the time through an innovative group format. These are their stories. 
Mocha Moms Member 3: My mother-in-law grew up in the segregated South and she still watches political shows. The older folks can't believe it ...

Mocha Moms Member 4: I bought a book for my six-year-old girl about Obama. In the book, it talks about him waking up early to do his homework.

Mocha Moms Member 2: How do we [take advantage of this change and] affect what happens outside this group?

In November 2008, these Mocha Moms members were clearly excited. Barack Obama had just been elected president, and they viewed this as a teachable moment for their children and their communities. Most important, they wanted to harness the momentum of the event to produce positive outcomes for their group chapters and beyond. But clearly this group was not starting from zero in terms of resources. There was decisive energy in the room and a strong sense of sisterhood among its members. This was a group with a vibrant and engaged history.

How did mothers' organizations like Mocha Moms-specifically MOPS, Mothers \& More, NAMC, and MomsRising-come into being in the associational landscape? How have the groups changed over time, in both scope and mission? What does each group's membership look like now, specifically with respect to its sociodemographic characteristics?

While mothers' groups have clearly emerged from the changing economic landscape of the past several decades, in each case, it took the initiative of one or a small set of leaders to begin a conversation about how they wanted their lives to be transformed through a new organizational community. Notably, these emergent leaders were each in a variety of circumstances, from working for pay, to transitioning into or out from the workforce, to staying at home. Nonetheless, across all five groups, the leaders perceived a sense of dissatisfaction, stress, and feeling of disenchantment with their lives as mothers. They therefore sought out mothers like themselves to find support and fulfill other needs that were so important to them at the time through an innovative group format. These are their stories. 


\section{Prayer and Motherhood: MOPS}

MOPS (Mothers of Preschoolers) is a Christian-based organization of chapters that focuses on the needs of mothers with preschoolers. ${ }^{1}$ While it does not have an explicit position on workplace flexibility, it welcomes both stay-at-home mothers and mothers who work for pay and encourages both groups to reach their full potential. Its website frequently presents articles on the challenges facing mothers who work for pay, including those mothers who wish to resolve these issues by establishing more flexible, at-home businesses. In terms of its meeting style, ideally, national MOPS asks that each local session include four components: social (food and fellowship), teaching from a biblical perspective, small-group discussion, and creative time. While attending meetings, MOPS members drop their children off at MOPPETS, a child care program oriented toward their developmental stage. The central goal behind the MOPS organization is to equip mothers to meet their own needs so they can ultimately make the world a better place. To fulfill this mission, MOPS aims to instill in its members qualities that will ultimately help them assume leadership positions outside the boundaries of the organization.

The organization began in 1973, when Maxine Shideler read a magazine article that described the challenges women faced in raising toddlers in the United States. Fascinated by this piece, she brought together seven other women to form MOPS in Wheat Ridge, Colorado. They met in a children's playroom at the Trinity Baptist Church, sitting together on tiny chairs made for their children. At this initial meeting, the women enjoyed each other's friendship and discussed their vision for the group. They wanted to create a safe space to be themselves as they faced the ups and downs of motherhood, and they knew immediately that they wanted their group to have a strong biblical dimension. At the core of their emerging belief system was the idea that mothering was a critical societal practice that until then had not been properly acknowledged or appreciated. They integrated discussion, religion, and craftwork as a way to build community and a sense of accomplishment among the core set of women who participated. They also believed that they could learn from each other as parents, and they asked fellow mother Naomi Michie to be the group's teaching leader. Once she agreed, Michie led thirty-minute instructional sessions on 
issues of importance to the women, and enabling feelings of security and self-esteem became paramount. From these initial meetings, the organization grew, and in 1981, it established a board of directors and incorporated as MOPS Outreach and later as MOPS Inc.

From this starting point, the number of groups ticked upward to approximately sixty by the early 1980s. Growth really exploded after Dr. James Dobson from Focus on the Family, an international Christian ministry group emphasizing family values, provided MOPS with an opportunity to describe its mission on his radio show. By the late 1980s as a result of publicity such as this, the number of MOPS chapters skyrocketed to over four hundred. By 1988, the group had established a presence abroad and changed its name to MOPS International. At this point, the board of directors realized that it could no longer rely on a team of volunteers to guide the group into the future; bursting at the seams, MOPS needed a more formal, paid staff. In 1989 the organization hired Elisa Morgan as its president.

Communication was key to its early success. In 1993 MOPS established a newsletter and then a magazine called MomSense, which was quickly followed by a radio show of the same name. The organization entered into a partnership with the Zondervan Publishing House in 1995 and formed a collaboration with Revell of the Baker Publishing Group in 2004. Both these initiatives were designed to keep the organization connected to companies that could enlarge the organization's outreach efforts to mothers across the globe. Finally, also of note during this time was the creation of Teen MOPS for adolescent mothers in 1995 and, in 1997, the introduction of an online presence for interested mothers.

As a Christian organization, according to its website, "MOPS International exists to encourage, equip and develop every mother of preschoolers to realize her potential as a woman, mother and leader in the name of Jesus Christ." There are numerous organizational principles that guide MOPS chapters. Although nondenominational, all MOPS chapters must affiliate with a local church or parachurch group, respect the heritage of the group, and practice good governance. All MOPS groups must also establish strong alliances with other institutions that could be helpful in achieving its goals. Last, all groups must adhere to MOPS' International Faith Position Statement, which outlines the group's beliefs as they relate to Jesus Christ. 
MOPS also has what it calls six ministry values that it aims to have permeate all its work. These emphasize (1) respecting the dignity of all human life; (2) equipping women to be all they can be; (3) valuing mothers and their contributions; (4) fostering all adult and parent-child relationships, as well as a relationship with Jesus Christ; (5) engaging in "lifestyle evangelism," whereby members are encouraged to bring others toward Jesus Christ through their daily choices, rather than overt preaching; and (6) fostering leadership development for women.

\section{All Mothers Are Not White: Mocha Moms}

Mocha Moms engages in the workplace flexibility policy arena by providing, as part of its national platform, particular entrepreneurial support for mothers with their own at-home businesses. ${ }^{2}$ In addition, it devotes resources to maintaining two national networks of mothers. Networks are simply subgroups within Mocha Moms that are dedicated to specific issue areas. These networks are connected via the Internet and promote the sharing of writing, personal stories, and advice. Mochas in Transition, the first network, offers services to any member experiencing caregiving or employment changes; Work at Home, the second network, does the same for mothers who either work at home for an employer or have their own home-based business.

The group began organically, when several stay-at-home mothers of color wanted to reach out to similar mothers located across the country. Cheli English-Figaro, an African American attorney, was married to a military physician when the air force relocated them to Bowie, Maryland, in 1992. English-Figaro found herself very isolated when she decided to leave paid employment to be a full-time mother to her newborn son in 1993. She had not planned to stay at home, and very few of her African American friends or family members understood why she would abandon her career to remain at home. In the fall of 1993, she joined the Officers' Wives Club, where she found only one other mother of color in similar circumstances. Still seeking companionship, she started attending meetings at La Leche League and continued networking with other groups such as Lawyers at Home and the Landover Memorial Baptist Church Mothers' Group (the church is now Woodstream Church). Although she did not find complete satisfaction in 
these other groups, her efforts at forging new relationships paid off in July 1994, when her son had his first birthday. With about thirty stayat-home mothers of color over at her townhouse to celebrate, she used the opportunity to present her vision for a long-term supportive community that she wanted to begin as soon as possible. The foundation of the group was officially laid.

Three years later, in Cheverly, Maryland, two other African American women were experiencing the same need to connect with other mothers of color who were staying at home with their children. Jolene Ivey and Karla Chutz (the wife of an air force officer), considering the advice of a friend, Dia Michels (a white stay-at-home mother), decided that the best way to link up with other African American stay-at-home mothers was through the production of a mother-oriented newsletter, which came to be called Mocha Moms. Through mutual friends, English-Figaro heard about this innovative newsletter and reached out to Ivey directly. English-Figaro introduced Ivey to her own group of stay-at-home mothers of color at a local McDonalds during the summer of 1997. Two weeks after this initial get-together, the new friends decided to move beyond the newsletter to form a new organization of like-minded stay-at-home mothers of color. At this first meeting at Ivey's home, English-Figaro was joined by Ivey, Chutz, Pauletta Handy (a friend of English-Figaro from the Landover Church mothers' groupl, and Nikki Haynes, a Muslim stay-at-home mother who had learned about the group through the Mocha Moms newsletter. Handy expressed a strong preference that the group have a Christian orientation; however, English-Figaro, Ivey, Chutz, and Haynes did not necessarily want to exclude mothers of other faiths. In the end, the majority decided that the group should remain secular. After this decision, Handy dropped out of the nascent organization, but soon another enthusiastic mother, Joby Dupree, took her place. A military wife herself, Dupree immediately discovered that she had a lot in common with English-Figaro and Chutz.

With these five women at its core, Mocha Moms started to grow and eventually became an incorporated organization. The mothers planned the organization and its activities at Ivey's house, at her church, and later, in local playgrounds. Jill Downing became another central player in the organization, helping English-Figaro develop a handbook that they hoped new groups would use in starting their own local chapters. English-Figaro and Downing later traveled all over the country to spread 